issn: $1808-799 \mathrm{X}$

ano 7 - número 9 - 2009

\title{
TRABALHO, REPRODUÇÃO SOCIAL E EDUCAÇÃO A PARTIR DA ONTOLOGIA DO SER SOCIAL
}

\author{
Frederico Costa ${ }^{1}$ - fredericojfcosta@yahoo.com.br
}

Com as pesquisas lukacsianas ${ }^{2}$ vem à tona a problemática ontológica como aspecto essencial da obra marxiana. Quando Lukács termina sua Estética na década de sessenta e, antes de iniciar sua projetada Ética, empreende, num esforço que consumiu aproximadamente seus últimos oito anos de vida, a produção de sua Ontologia do Ser Social como uma ampla introdução à citada Ética.

Lukács entende que Marx instaura os fundamentos de uma ontologia de novo tipo, pois Marx pensa as relações do homem com sua história não de uma maneira especulativa, mas da perspectiva do ser social historicamente determinado, o que conduz a uma orientação radicalmente nova tanto das relações do indivíduo com sua história, como com a história do gênero - dimensões imanentes que constituem o processo histórico global. Assim, com Marx, pela primeira vez torna-se possível fundamentar teórica e praticamente - o que é necessariamente mediado pela luta de classes e pela política - a possibilidade da humanidade decidir para

\footnotetext{
${ }^{1}$ Doutor em Educação, professor da Faculdade de Educação de Itapipoca da Universidade Estadual do Ceará - FACEDI/UECE e pesquisador colaborador do Instituto de Estudos e Pesquisas do Movimento Operário - IMO/UECE.

2 "Pode-se até afirmar que o fato de voltar-se para a ontologia constitui, para ele, uma enérgica reação contra certa hegemonia do neopositivismo no cenário filosófico: diante das tentativas de homogeneização cada vez mais explícita da vida social, submetida aos imperativos do cálculo e da quantificação, a ontologia do ser social pretende dar destaque à heterogeneidade e à diferenciação extremas do tecido social, opondo uma negação clara ao confisco do indivíduo e à manipulação." (TERTULIAN, 1996, p. 57).

${ }^{3}$ Nesse projeto, a Ontologia do Ser Social aparecia como o prelúdio necessário de uma Ética. Até os últimos momentos da vida, o filósofo alimentou a esperança de realizá-lo, isto é, dar uma seqüência lógica à sua Ontologia, como testemunha uma carta de 30 de dezembro de 1970, endereçada a Ernest Bloch [...] Lukács escrevia ao seu amigo de juventude que o assunto do trabalho que projetava escrever era sobre die Entwicklung der menschlichen Gattungsmässigkeit (o desenvolvimento da generidade humana). A Ontologia, aí compreendidos os Prolegômenos, culmina efetivamente numa teoria do gênero humano - distinguindo entre Gattungsmässigkeit an-sich e Gattungsmässigkeit fürsich (entre generidade em-si e generidade para-si), e seria por meio da Ética que deveria desenvolver esta problemática. (TERTULIAN, 1996, p. 54-55).
} 
issn: $1808-799 \mathrm{X}$

ano 7 - número 9 - 2009

onde ir: capitalismo/barbárie ou comunismo/emancipação humana; isso porque em Marx não há nenhuma categoria anistórica - ordem cosmológica, Deus, natureza humana - que faça a história pelos homens impondo uma determinação ontológica insuperável como o "lugar natural" aristotélico, o Deus medieval ou a "natureza humana" dos filósofos modernos.

Marx, para Lukács, elabora uma ontologia crítica - uma ontologia do ser social - ao próprio mundo que a produziu, e propõe a construção de outra sociabilidade, que é a negação do existente e não a simples justificativa da realidade tal como ela é.

A ontologia do ser social inaugurada por Marx, segundo Lukács ${ }^{4}$, ao afirmar a mutabilidade do existente, critica o mundo que a originou, no caso, a sociedade burguesa. Com a superação do capitalismo há a possibilidade de iniciar a produção da história - sairmos da pré-história - e não o fim desta. Portanto, muda toda a reflexão e o tratamento de todas as categorias ontológicas. Tudo se integra na processualidade histórica, nada podendo ser anistórico. Categorias como, por exemplo: essência, fenômeno, singular, particular, universal, mediação e continuidade, são redimensionadas tendo como pressuposto que não são pensadas aprioristicamente em relação ao processo histórico que lhe dá efetividade, isto é, elas não têm sentido a não ser em suas existências concretas e nas suas possibilidades.

Nesse sentido, algo de substancial vem sendo produzido por vários estudiosos da ontologia do ser social como, por exemplo, José Paulo Netto, José Chasin, Sérgio Lessa e Ivo Tonet, além de esforços coletivos como o da linha Marxismo, Educação e Luta de Classes do Programa de Pós-Graduação em

\footnotetext{
4 "Desde a leitura dos Manuscritos de 1844 até o final de sua vida, a trajetória intelectual de Lukács evolui para a elaboração de uma proposta de recuperação de Marx que pusesse em relevo o caráter radicalmente revolucionário da sua obra. Contra todas as concepções que cancelam a possibilidade ontológica da revolução socialista, Lukács se propõe a demonstrar como, por quais mediações, os homens são os únicos responsáveis por sua história, de tal modo que não há nenhuma justificativa para a ordem burguesa venha a ser o fim da história, de tal modo que não há nenhuma justifica para que a ordem burguesa venha a ser o 'fim da história', tanto na versão hegeliana quanto na farsa de Fukuyama." (LESSA, 2001, p. 85).
} 
issn: $1808-799 \mathrm{X}$

ano 7 - número 9 - 2009

Educação Brasileira da Faculdade de Educação da Universidade Federal do Ceará e do Instituto de Estudos e Pesquisas do Movimento Operário da Universidade Estadual do Ceará, entre outros no Brasil. Isso, no nosso entender, já possibilita o ensaio de alguns passos na constituição de uma reflexão pedagógica fundamentada na ontologia do ser social'.

Nessa perspectiva, o objetivo deste artigo é, partindo da ontologia do ser social, em especial das contribuições do último Lukács $^{6}$ (1981), situar introdutoriamente os nexos entre trabalho, reprodução social e educação. Trata-se, de fato, da identificação de momentos essenciais de um processo que vincula as três categorias citadas, o que devido à contradição entre a complexidade da temática e os limites próprios de um artigo científico, deixa de fora mediações, que, no entanto, não descaracterizam a natureza do empreendimento proposto.

O presente texto divide-se em três momentos, que buscam identificar as mediações que conectam educação e reprodução no ser social, que é fundado pelo trabalho. O primeiro momento identifica o trabalho como fundamento ontológico do ser social e aponta para os vínculos existentes deste com a reprodução social. O segundo momento parte da reprodução social como uma totalidade dialeticamente polarizada entre gênero e indivíduo. O terceiro momento apresenta a educação, uma práxis que não se confunde com o trabalho em sentido ontológico, como uma mediação particularizadora essencial entre $o$ universal e o singular na continuidade do ser social.

\footnotetext{
${ }^{5}$ Exemplo disso foi o I Congresso de Ontologia do Ser Social e Educação, realizado entre os dias 28 de novembro e $1^{\circ}$ de dezembro de 2007, no Instituto de Biociências, Letras e Ciências Exatas da Universidade Estadual Paulista - UNESP, em São José do Rio Preto.

${ }^{6}$ No Lukács marxista é possível identificar cinco etapas principais de sua reflexão teórica. Primeira fase (1919-1923): adoção do marxismo sob a forma de historicismo abstrato, embasando um ativismo revolucionário, produção do clássico "História e consciência de classes". Segunda fase (1924-1933): do repúdio de "História e consciência de classe", passando pelas "Teses de Blum", pela estada em Berlim e início do exílio na URSS. Terceira fase (1933-1945): etapa de permanência na URSS; mobilização total contra o nazi-fascismo, paralela às lutas intrapartidárias; trabalhos centrados sobre a arte e literatura, dedicando grande esforço à análise filosófica. Quarta fase (1945-1956): do retorno a Budapeste à preparação do levante de outubro de 1956; etapa de vasta publicação referente à literatura e a problemas filosóficos, bem como de crítica oblíqua ao stalinismo. Quinta Fase (19561971): última etapa intelectual; centra-se na elaboração sistemática da sua Estética, na produção de crítica avulsa (literária e política) e na preparação da Ontologia do ser social.
} 


\section{frabalnonecessário \\ issn: $1808-799 \mathrm{X}$ \\ ano 7 - número 9 - 2009}

\section{Trabalho e reprodução do ser social}

O trabalho é o fundamento ontológico do ser social, sendo a matriz das objetivações ${ }^{7}$ pelas quais o mundo dos homens se realiza concretamente. É através do trabalho, mediação necessária entre homem e natureza, que o homem se destaca da esfera natural e instaura um novo plano ontológico, que se caracteriza por níveis crescentes de socialização ${ }^{8}$.

A possibilidade de tal processo ocorre porque "[...] os atos de trabalho, necessária e continuamente, remetem para além de si mesmos." (Lukács, 1981, p. 135), isto é, o trabalho produz sempre o novo9. Por outro lado: "O trabalho [...] como categoria desenvolvida do ser social, só pode chegar à sua verdadeira e adequada existência num complexo social que se mova e se reproduza processualmente" (Lukács, 1981, p. 135).

No processo de trabalho a produção de um objeto não é uma simples modificação da realidade, pois cada objetivação em seu processo de efetivação

\footnotetext{
7 "[...] o trabalho tem um significado fundante para a especificidade do ser social, do qual ele funda todas as determinações. Todo fenômeno social [...] pressupõe direta ou indiretamente, às vezes muito indiretamente, o trabalho com todas as suas conseqüências ontológicas." (Lukács, 1981, p. 135).

${ }^{8}$ Nesse processo, é importante destacar, que a capacidade de projetar antecipadamente (teleologia) é a lei determinante do modo de operar da atividade humana de produzir objetos úteis à satisfação de suas necessidades. Daí Lukács (2004, p. 62) destacar que: "[...] através do trabalho, se realiza uma posição teleológica dentro do ser material enquanto surgimento de uma nova objetividade. Assim é que o trabalho se converte, por um lado, em modelo de toda práxis social na medida em que nesta ainda quando através de mediações muito diversificadas - se realizam sempre posições teleológicas, em última instância, de ordem material".

9 "À medida que progride, descobrindo e realizando coisas novas, novas necessidades, novos caminhos para satisfazê-las, o processo de trabalho provoca na sociedade, juntamente à própria difusão e aperfeiçoamento crescentes [...]." (Lukács, 1981, p. 154).
} 


\section{trabalnonecessário}

issn: $1808-799 \mathrm{X}$

ano 7 - número 9 - 2009

transforma, além da materialidade natural, o próprio sujeito que conduz a transformação, o qual adquirindo novas habilidades e conhecimentos se exterioriza como sujeito. Portanto, a partir de cada ato de trabalho que produz uma objetivaçãoexteriorização, surge uma nova situação tanto no aspecto objetivo como no aspecto subjetivo.

Objetivamente, ao mundo dos homens é incorporado um novo objeto antes inexistente, o qual é inserido no contexto social já existente, trazendo possibilidades novas e até desconhecidas para seus criadores. Isso, como resultado do fato do novo influenciar e ser influenciado pela totalidade concreta. Para exemplificar tal fato ontológico, pensemos em descobertas como as do fogo, do ferro, da pólvora, da imprensa, da eletricidade e da energia nuclear, com suas implicações sociais objetivas, as quais acabam revelando que em cada processo de objetivação há uma tendência real de generalização dos resultados alcançados.

Por outro lado, subjetivamente, a própria consciência encontra-se mais enriquecida de conhecimentos e habilidades, inimagináveis antes do ato de trabalho, o que impulsiona o indivíduo, pelo próprio convívio social, a generalizar suas novas capacidades. Assim, foram se constituindo por meio do acúmulo incessante de conhecimentos parciais, objetivações universais como a filosofia, a ciência e a tecnologia. Esse movimento amplia-se com a maior complexidade das relações sociais e integração das comunidades humanas, o que acaba explicitando e desenvolvendo o complexo social da educação.

As mudanças objetivas e subjetivas advindas do processo de objetivaçãoexteriorização impõem irreversivelmente ao indivíduo, novos atos teleologicamente orientados para responder às novas situações criadas por suas ações, o que implica necessariamente em novos atos de objetivação-exteriorização, reiniciando o mesmo processo em patamares sociais cada vez mais avançados, pois as novas objetivações só podem vir a ser enquanto efetivação material de finalidades ideais induzidas pela nova situação que incorporou socialmente o resultado da objetivaçãoexteriorização anterior. Isso indica que ao transformar a realidade, os atos individuais tendem a agir sobre outros indivíduos partícipes da comunidade, e com o 
issn: $1808-799 \mathrm{X}$

ano 7 - número 9 - 2009

desenvolvimento histórico passa a abarcar totalidades sociais cada vez maiores até atingir a humanidade em conjunto, o que só se tornou possível como advento do capitalismo e do mercado mundial ${ }^{10}$.

Em síntese, a orientação à generalização presente no trabalho leva pela mediação da reprodução social, ao surgimento de tendências histórico-genéricas com sua própria legalidade ${ }^{11}$, que levam as sociabilidades a se afastarem cada vez mais das situações originárias. Como propriedade inerente à atividade humana, as posições práticas teleologicamente orientadas, surgidas da escolha entre opções, ao se inserirem na malha das relações sociais, necessariamente se generalizam em complexos mediadores crescentemente sociabilizados que passam a integrar 0 conteúdo, tanto de cada individualidade constituída socialmente como de cada formação social, composta em última instância por atos singulares.

\section{A reprodução social e a dialética gênero-indivíduo}

Há uma distinção essencial entre a natureza de cada ato singular e a tendência histórico-genérica. Enquanto 0 ato singular tem na sua gênese uma posição teleológica, a tendência genérica realiza-se como causalidade sem nenhum vestígio de teleologia ${ }^{12}$. Por isso, a síntese dos atos singulares em tendências histórico-genéricas $^{13}$, que condicionam as decisões alternativas singulares,

\footnotetext{
10 "Só quando surge e se intensifica o mercado mundial, o gênero humano ascende à ordem do dia como problema universal que envolve todos os homens." (Lukács, 1981, p. 149).

11 "[...] na reprodução no interior do ser social, determinadas tendências legais, emergentes da essência da própria coisa, terminam, necessariamente por se afirmar nas mais diversas condições objetivas e subjetivas." (Ibidem, p. 145).

12 "[...] a legalidade no ser social tem uma dupla face: de um lado, a lei geral tende inevitavelmente a transformar as categorias deste ser em categorias sociais - feitas pelos homens, visando à vida dos homens - de outro as tendências que aqui se apresentam não têm caráter teleológico, embora se componham de tendências objetivo-universais a partir da posições teleológicas singulares." (Ibidem, p. 150).

"[...] toda posição teleológica coloca em movimento cadeias causais que são mais numerosas e diversas do quanto se desejaria com aquela posição, a síntese social vai além de todas as posições singulares, realiza - em termos gerais e objetivos - mais do que estava contido nelas [...]." (Lukács, 1981, p. 150).
} 
issn: $1808-799 \mathrm{X}$

ano 7 - número 9 - 2009

processa-se de maneira independente da consciência dos indivíduos que por sua atividade fazem a história ${ }^{14}$.

Os indivíduos muitas vezes se escandalizam com os produtos do capitalismo decadente - como a miséria e a violência - sem ter consciência de que seus atos cotidianos nas relações mercantis, na passividade diante das ofensivas do capital contra o trabalho, e na participação ativa na esfera da cidadania como horizonte de convívio entre os homens, convergem para a produção e reprodução das desigualdades sociais. Porém, o próprio avanço e complexificação das relações sociais, tornam possíveis aos indivíduos a aquisição de uma consciência, restrita ou totalizante, mas sempre dentro de coordenadas sociais concretas, de como seus atos singulares sintetizam-se em determinadas tendências histórico-genéricas.

A partir dessa consciência da natureza de uma formação social concreta, os indivíduos passam a compreender que possuem a capacidade de por meio de uma mudança nos seus atos, intervir no desenvolvimento histórico global, acelerando ou modificando uma ou várias de suas tendências ${ }^{15}$. No entanto, isso não significa que os homens possam ter o controle absoluto das conseqüências de seus atos históricos, pois não há uma identidade entre sujeito e objeto, isto é, não há coincidência entre teleologia e produto objetivado. Tanto as massas jacobinas como os trabalhadores bolchevistas, por exemplo, não tinham condições de visualizar com certeza absoluta a resultante final de seus atos revolucionários.

O interessante, na perspectiva ontológica da reprodução social, é que o desenvolvimento social é mediado necessariamente pelos atos singulares dos indivíduos historicamente determinados, isto é, todo desenvolvimento social tem como pressuposto e condição a possibilidade de uma maior ampliação da esfera da

\footnotetext{
14 "[...] a reprodução social, em última análise, se realiza nas ações dos indivíduos - no imediato a realidade social se manifesta no indivíduo -, todavia estas ações, para se realizarem, se inserem, por força das coisas, em complexos relacionais entre homens, os quais uma vez atingidos possuem uma determinada dinâmica própria; isto é, não só existem, se reproduzem, operam na sociedade independente da consciência dos indivíduos, mas dão também impulsos, direta ou indiretamente, mais ou menos determinantes às decisões alternativas." (Ibidem, p. 156).

${ }^{15}$ As posições teleológicas "[...] não são capazes de transformar a universalidade da lei e seus efeitos universalmente casuais - do ponto de vista do indivíduo singular sujeito à lei -, porém criam para os singulares, uma margem de manobra que pode, em certa medida, modificar o efeito da lei sobre eles." (Ibidem, p. 164).
} 
issn: $1808-799 \mathrm{X}$

ano 7 - número 9 - 2009

individualidade. Entre os processos de complexificação das relações sociais e de complexificação das individualidades, existe um nexo ontológico e uma dialética que constitui os dois pólos da reprodução social, isto é, de um lado, o processo reprodutivo da totalidade e, de outro lado, os indivíduos singulares cuja reprodução enquanto singularidades constituem a base de ser da reprodução total.

O vínculo ontológico entre essas duas processualidades que expressam a polaridade da reprodução social é a consciência. Ela é o elemento central da continuidade do ser social que tem como pressuposto básico a produção incessante do novo - o que consolida a diferença entre a reprodução social da simples reprodução biológica. Como afirma o pensador húngaro:

É evidente que tal movimento de continuidade deve encontrar seu medium na consciência dos homens, mas igualmente evidente é que tal consciência é considerada como componente de fato do ser social e não poderá jamais ser avaliada com critérios gnosiológicos abstratos. (Lukács, 1981, p. 65).

Por isso, a continuidade do mundo dos homens é capaz de uma riqueza de possibilidades bem maior dos que as outras esferas do ser - orgânica e inorgânica -, como a produção de valores e a esfera da liberdade. E não há nada de fortuito nessas possibilidades. Elas têm como solo genético a capacidade da consciência, como medium ${ }^{16}$ da continuidade do ser social, de influir sobre a própria continuidade trazendo resultados expressivos dentro de coordenadas históricas concretas.

\footnotetext{
${ }^{16}$ Tomemos como exemplo um ato de trabalho singular para identificarmos a consciência como medium da continuidade. $O$ indivíduo age sobre o objeto de trabalho baseado em conhecimentos acumulados pela experiência. No entanto, no presente, novas circunstâncias apresentam-se, tanto em relação à necessidade que o conduziu ao ato de trabalho, como ao contexto social e ao objeto natural a ser transformado. Além disso, a parte da natureza a ser transformada se constitui como objeto de realização de uma posição teleológica que se dirige necessariamente para o futuro. Em razão disso, no processo da objetivação os conhecimentos acumulados são testados, renovados e até superados, para que possam enfrentar a nova realidade presente e realizar eficazmente a posição teleológica para o futuro. Assim, pela dialética entre o passado, o presente e o futuro, presente, não só no trabalho, mas em todas as formas de práxis, se processa a continuidade. Logo o medium (mediação fundamental) desta vinculação constantemente posta e reposta em níveis de complexidade crescente é precisamente a consciência.
} 


\section{trabalnonecessário}

issn: $1808-799 \mathrm{X}$

ano 7 - número 9 - 2009

Dito isso, podemos indicar alguns pontos da reprodução social necessários para compreender a particularidade do complexo da educação.

Primeiro, a reprodução social do processo concreto de autoconstrução do mundo dos homens é a totalidade composta de processualidades contraditórias que têm como fundamento último o trabalho, e por meio das quais o homem se cria constantemente como ser social ontologicamente distinto da natureza.

Segundo, há uma dialética entre trabalho e reprodução social. O trabalho é o fundamento ontológico e condição de existência do ser social, logo da própria reprodução deste. No entanto, o trabalho só se efetiva no contexto da reprodução social. Tal nexo ontológico tem sua raiz no fato dos dois complexos - trabalho e reprodução social - terem como fundamento as decisões alternativas, teleologicamente orientadas, de indivíduos concretos em situações historicamente determinadas.

Terceiro, o ser social e suas tendências histórico-genéricas, como criação humana, alicerçam-se nas atividades individuais que embora necessariamente concretas e singulares em seu caráter imediato por sua natureza social, são explicitações parciais do gênero humano, gerando e reproduzindo constantemente e maneira cada vez mais ampliada e complexa o mundo dos homens.

Quarto, o processo reprodutivo do ser social, essencialmente unitário, é composto por dois pólos, gênero humano e indivíduo. Diferentemente do ser biológico, no qual o gênero de certa forma é diretamente expresso pela reprodução de suas singularidades, no ser social a reprodução de gênero humano, exige e é fundado em individualidades crescentemente mais complexas, que de sua parte não são simples reproduções singulares do gênero ${ }^{17}$.

\footnotetext{
17 “[...] à medida que a generalidade humana se eleva a patamares crescentes de consciência, à medida que o gênero humano se constrói cada vez mais como genérico e social, as individualidades necessariamente se complexificam. Elas também elevam o seu nível de autoconsciência. Ao fazê-lo lançam as bases para, objetiva e subjetivamente, construírem uma distinção cada vez mais acentuada entre a reprodução do indivíduo e a reprodução do gênero." (Lessa, 2001, p. 91-92).
} 


\section{trabalnonecessário}

issn: $1808-799 \mathrm{X}$

ano 7 - número 9 - 2009

Quinto, por ter como elemento indispensável as posições teleologicamente postas, a continuidade do mundo dos homens tem como medium a consciência, ou seja, o processo de acumulação de objetivações e mediações tem nela seu órgão primário. O que não significa nenhuma perversão idealista ou espiritualista, pois a consciência singular pressupõe um cérebro e a concretude das relações sociais para surgir e se desenvolver, "[...] em sua imediadicidade a consciência é sempre aquela de indivíduos concretos." (Lukács, 1981, p. 91).

Com isso, não queremos afirmar o caráter de epifenômeno social da consciência, pois esta não apenas reflete ou assimila o que existe, já que constitui o canal por meio do qual os indivíduos elaboram suas decisões alternativas frente às exigências do real. Tanto faz, nesse sentido, que os indivíduos concretos queiram modificar ou manter o existente, a consciência sempre atuará de maneira ativa, num ou noutro caso, atualizando a experiência passada e acumulando novas, sempre para enfrentar as imposições do presente e as possibilidades do futuro.

Então, já que a totalidade social é a síntese de atos singulares teleologicamente orientados e que cada individualidade é sempre concreta, ou seja, é resultante das relações dela com o mundo, coloca-se uma questão essencial para a reprodução social: a apropriação por parte dos indivíduos das objetivações produzidas pelo trabalho e pelas diversas formas de práxis social.

\section{A educação como mediação necessária da reprodução social}

A substância do gênero humano, como expressão do processo de devir do homem, é constituída pelo conjunto de objetivações produzidas pela atividade humana na história que se configuram nos simples objetos materiais e nas mais bem elaboradas produções espirituais, nas mais elementares e nas mais complexas mediações, na heterogeneidade das relações sociais e na diversidade dos indivíduos. Em cada período histórico, cada totalidade social condensa o conjunto de 


\section{trabalnonecessário}

issn: $1808-799 \mathrm{X}$

ano 7 - número 9 - 2009

atributos e possibilidades, tanto positivos como negativos, de cada formação social concreta. Indica por assim dizer, os níveis de humanização e estranhamento contidos nas relações sociais predominantes.

A totalidade social no seu pólo genérico é o patrimônio comum de todos os homens, não residindo em nenhum indivíduo particular, mas, simultaneamente, existindo na totalidade de objetivações das quais cada indivíduo deve apropriar-se de um quantum mínimo, em cada fase histórica, para se constituir enquanto homem. Isso porque, diferentemente do ser biológico, o resultado da humanização do homem, seu afastamento crescente das "barreiras naturais" e sua maior generidade, não se acumulam organicamente nem são transmitidos geneticamente. É claro que, como é impossível romper com a naturalidade do homem, o que é transmitido pela herança genética são as características biológicas do homo sapiens. Já as determinações do gênero humano têm um conteúdo extra-biológico, por serem essencialmente sociais.

Portanto, a continuidade e o desenvolvimento das determinações do gênero humano, o universo de objetivações que constituem e perfazem uma exigência da continuidade do próprio ser social, exigem uma mediação social específica para se efetivar - mediação essa responsável pela apropriação por parte dos indivíduos das objetivações necessárias tanto para a manutenção e desenvolvimento da totalidade do ser social como para constituição de individualidades mais complexas para responder às exigências das relações concretas. O que deve se realizar pelas próprias características do ser social, por meio da consciência, ou seja, pela apropriação subjetiva de um conjunto de objetivações socialmente postas, que deverão municiar o indivíduo diante das novas situações que exigirão novas posições teleológicas.

Dessa maneira, a reprodução do ser social, sua continuidade, exige um tipo de mediação responsável por expressar na subjetividade do indivíduo os patamares históricos do gênero humano. Devido a descontinuidade entre gênero e indivíduos, a reprodução do ser social exige uma mediação particularizadora entre generidade e individualidade, que numa dialética de transmissão/apropriação 
issn: $1808-799 \mathrm{X}$

ano 7 - número 9 - 2009

processe a continuidade do ser social de geração a geração e do universal para o particular. Tal mediação, própria da reprodução social, é a educação.

É importante destacar que a educação no sentido ontológico, não é trabalho, mas um tipo específico de práxis social integrante do complexo da reprodução social ${ }^{18}$. O trabalho é necessariamente uma posição teleológica primária por expressar o metabolismo entre o homem e a natureza, visando com finalidades humanas objetos naturais. A práxis educativa vincula-se àquele tipo de posição teleológica que busca incidir sobre a consciência de outros indivíduos para impeli-los a executar posições desejadas ${ }^{19}$. Nesse sentido, enfatiza Tonet (2005, p. 218):

O ato educativo, ao contrário do trabalho, supõe uma relação não entre um sujeito e um objeto, mas entre um sujeito e um objeto que é ao mesmo tempo também sujeito. Trata-se aqui, de uma ação sobre uma consciência visando induzi-la a agir de determinada forma. No trabalho, se dispusermos dos conhecimentos e das habilidades necessários e realizarmos as ações adequadas, é certo que, salvo intervenção do acaso, atingiremos o objetivo desejado. No caso do ato educativo, o mesmo conjunto de elementos está longe de garantir a consecução do objetivo, pois não podemos prever como reagirá o educando.

Então a função da práxis educativa funda-se na necessidade do processo reprodutivo, que constantemente gera o novo, de impor situações que exigem além certos tipos de respostas, a reprodução e desenvolvimento de uma série de objetivações necessárias para a continuidade social.

Cada formação social específica - da comunidade primitiva ao capitalismo - cobra dos indivíduos determinadas formas de pensar, produzir e agir imprescindíveis a cada tipo de sociedade. Noutras palavras, as forças sociais

\footnotetext{
${ }^{18}$ Aqui reside um ponto para possíveis polêmicas. Mas, quando indicamos que educação não é trabalho no sentido ontológico, afirmamos que o complexo educacional não funda o ser social, embora, no nosso ponto de vista, não haja sociedade sem educação, por ser esta uma mediação essencial da reprodução social. Além do mais, no capitalismo a educação torna-se mercadoria e a atividade docente torna-se trabalho assalariado, podendo ser trabalho produtivo (gerador de maisvalia) ou improdutivo, dependendo das circunstâncias concretas em que se realiza. Essa possibilidade da atividade docente tornar-se trabalho abstrato para acumulação capitalista não nega sua natureza ontológica de mediação entre consciências e não entre o homem e a natureza.

19 "As posições teleológicas necessárias são [...] de duas formas: aquelas que visam transformar, com finalidades humanas, objetos naturais (no sentido mais amplo do termo, inclusive, pois a força da natureza) e aquelas que tencionam incidir sobre a consciência dos outros homens para impeli-los a executar as posições desejadas." (LUKÁCS, 1981, p. 155).
} 


\section{trabalhonecessário}

issn: $1808-799 \mathrm{X}$

ano 7 - número 9 - 2009

dominantes condicionam um conjunto de posições teleológicas responsáveis pelas decisões alternativas individuais, indicando as desejáveis e as não desejáveis. Para Lukács (1981, p. 153), "[...] a problemática da educação reenvia à questão sobre a qual ela se funda: a sua essência consiste em influenciar os homens a fim de que, frente às novas alternativas da vida, reajam de modo socialmente desejado."

Portanto, o primeiro elemento da educação centra-se na formação social do comportamento, pois a sua essência consiste em influenciar os homens a fim de que, frente às novas alternativas da vida, reajam de modo socialmente desejado. $A$ práxis educacional intenta, como mecanismo da reprodução social, induzir as posições teleológicas dos indivíduos para determinadas decisões compatíveis com as exigências de determinada formação social, mas também:

Toda sociedade reclama dos próprios membros uma dada massa de conhecimentos, habilidades, comportamentos etc.; conteúdo, método, duração etc. da educação em sentido estrito são conseqüências das necessidades sociais assim surgidas. (Lukács, 1981, p. 153).

O que quer dizer que, só com a apropriação, o domínio e o desenvolvimento das objetivações passadas, a práxis social em suas diversas esferas, pode avançar, inclusive produzindo o novo, a partir da inadequação de certas objetivações e da integração de novas descobertas. Além disso, educação é uma ponte entre o acúmulo de objetivações das gerações passadas e o presente que precisa dar respostas novas a novas situações próprias da construção permanente do futuro. A importância das objetivações do passado está nas potencialidades reveladas pelas necessidades do presente. Por isso, a chave da compreensão da anatomia do macaco é a anatomia do homem. É o futuro do processo reprodutivo que define quais objetivações e para que setor social - no caso das sociedades classistas - devem ser transmitidas e apropriadas pelos indivíduos, a fim de que estes possam se "[...] tornar aptos a reagir adequadamente a eventos e situações imprevisíveis, novas, que apresentar-se-ão mais tarde nas suas vidas." (Lukács, 1981, p. 152). 


\section{trabalnonecessário}

issn: $1808-799 \mathrm{X}$

ano 7 - número 9 - 2009

Assim, a práxis educativa intenta produzir individualidades de acordo com as exigências de determinado tipo de sociedade, o que ocorre pela sua influência sobre o campo das decisões individuais, e também busca mediar o processo de apropriação por parte dos indivíduos da experiência humana acumulada. Sendo a produção de individualidades compatíveis com as formas concretas do ser social o eixo que impulsiona, coordena e determina o processo de transmissão e apropriação no conjunto de objetivações mínimas para a continuidade de cada formação social.

Além de estar sempre voltada para as necessidades do ser social historicamente determinado, a educação é algo imanente ao processo de reprodução social, pois "[...] a educação do homem - no sentido mais lato - em verdade não é jamais totalmente concluída." (Lukács, 1981, p. 152). Noutras palavras, não existe ser social, por mais primitivo que seja, sem educação. Os novos momentos históricos advindos em última instância da capacidade do trabalho de sempre produzir o novo, e que é ampliado pelo conjunto da práxis social, necessitam de um processo constante de transmissão/apropriação de velhas e novas objetivações, seja de maneira espontânea ou sistematizada para que os indivíduos possam dar respostas às novas circunstâncias. Tal processo não ocorre de maneira aleatória ou fortuita, pois o seu limite está ancorado no movimento de desenvolvimento da totalidade social. Por isso, tanto a formação de indivíduos socialmente aceitáveis como a transmissão de um conjunto de conhecimentos, habilidades e valores, tem como lastro a necessidade ontológica da reprodução social, que seleciona as características da individualidade, o que deve ser preservado do passado e quais as novas objetivações serão incorporadas no fluxo da práxis social.

É óbvio que com o desenvolvimento das forças produtivas, a complexificação do ser social - e das próprias objetivações que o compõem -, e o surgimento das classes sociais, o processo educacional se complexifica e fica subordinado cada vez mais à divisão social do trabalho. A relação entre a educação espontânea - que sempre existirá por ser inerente às relações sociais e à práxis coletiva - e a educação formal e sistematizada, se torna mais hierarquizada e 


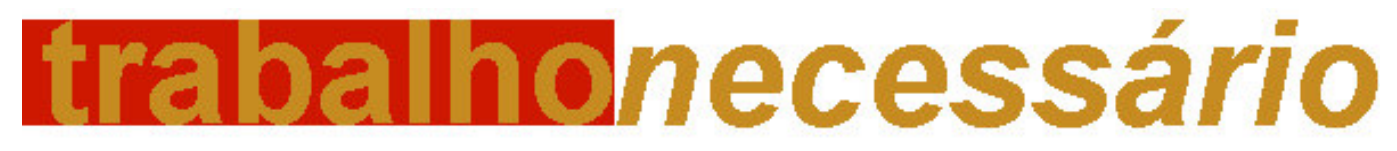

issn: $1808-799 \mathrm{X}$

ano 7 - número 9 - 2009

complexa, por estarem cada vez mais mediadas, pelo menos nas formações classistas, por determinações de classe e poder.

Referências Bibliográficas

LESSA, Sérgio. Lukács e a Ontologia: uma introdução. Outubro, São Paulo, n. 5, p. 83-100, 2001.

LUKÁCS, György. Per una Ontologia dell'Essere Sociale. Roma: Ed. Riuniti, 1981, v. 1 e 2.

. Ontologia del Der Social: el trabajo. Buenos Aires: Herramienta, 2004.

TERTULIAN, Nicolas. Uma apresentação à Ontologia do ser social, de Lukács. Crítica Marxista, São Paulo, n. 3, p. 54-69, jun. 1999.

TONET, Ivo. Educação, Cidadania e Emancipação Humana. ljuí: Unijuí, 2005. 